"This is the peer reviewed version of the following article: Cheeveewattanagul, N.; MoralesNarváez, E.; Hassan, A.; [et al.]. Straightforward Immunosensing Platform Based on Graphene Oxide-Decorated Nanopaper: A Highly Sensitive and Fast Biosensing Approach. Advanced Functional Materials, 27(28) 2017, which has been published in final form at https://doi.org/10.1002/adfm.201702741.

This article may be used for non-commercial purposes in accordance with Wiley Terms and Conditions for Use of Self-Archived Versions."

DOI: 10.1002/ ((please add manuscript number))

Article type: Full Paper

\title{
Straightforward Immunosensing Platform based on Graphene Oxide-Decorated Nanopaper: A Highly Sensitive and Fast Biosensing Approach
}

Nopchulee Cheeveewattanagul*, Eden Morales-Narváez ${ }^{\star}$,Abdel-Rahim H.A. Hassan, José Francisco Bergua, Werasak Surareungchai, Mithran Somasundrum, Arben Merkoçi*

Nopchulee Cheeveewattanagul, Dr. E. Morales-Narváez, Dr. A. H.A. Hassan, J. F. Bergua, Prof. A. Merkoçi

Nanobioelectronics and Biosensor Group, Catalan Institute of Nanoscience and

Nanotechnology (ICN2), CSIC. The Barcelona Institute of Science and Technology,

Campus UAB, Bellaterra, 08193, Barcelona, Spain.

E-mail: arben.merkoci@icn2.cat

N. Cheeveewattanagul, Dr. W. Surareungchai

Division of Biotechnology, School of Bioresources and Technology, King Mongkut's

University of Technology Thonburi, Bangkhuntien Campus, Bangkok, 10150,

Thailand.

Dr. E. Morales-Narváez

Biophotonic Nanosensors Laboratory, Centro de Investigaciones en Óptica A. C., Loma del Bosque 115, Lomas del Campestre, León, Guanajuato, 37150, México.

Dr. A. H.A. Hassan

Food Hygiene Department, Faculty of Veterinary Medicine, Beni-Suef University, Beni-Suef 62511, Egypt.

Dr. W. Surareungchai

Nanoscience \& Nanotechnology Graduate Program, King Mongkut's University of

Technology Thonburi, Bangkhuntien Campus, Bangkok, 10150, Thailand

Dr. M. Somasundrum

Biochemical Engineering and Pilot Plant Research and Development Unit, National Center for Genetic Engineering and Biotechnology, National Science and Technology Development Agency at King Mongkut's University of Technology Thonburi (Bangkhuntien Campus), Bangkok, 10150, Thailand.

Prof. A. Merkoçi

ICREA - Institució Catalana de Recerca i Estudis Avançats, Barcelona 08010, Spain.

*These authors contributed equally.

Keywords: nanocomposites, optical biosensors, biophotonics, paper-based devices, immunoassay, diagnostics

Immunoassays are nowadays a crucial tool for diagnostics and drug development. However they often involve time-consuming procedures and need at least two antibodies in charge of the capture and detection processes respectively. We report a nanocomposite based on graphene oxide-coated nanopaper (GONAP) facilitating an advantageous immunosensing platform using a single antibody and without the need for washing steps. The hydrophilic, porous and photoluminescence-quenching character of GONAP allows for the adsorption and quenching of photoluminescent quantum dots nanocrystals complexed with antibodies (AbQDs), enabling a ready-to-use immunosensing platform. The photoluminescence is recovered upon immunocomplex (antibody-antigen) formation which embraces a series of interactions 


\section{WILEY-VCH}

(hydrogen bonding, electrostatic, hydrophobic and Van der Waals interactions) that trigger desorption of the antigen-Ab-QD complex from GONAP surface. However, the antigen is then attached onto the GONAP surface by electrostatic interactions leading to a spacer (greater than c.a. $20 \mathrm{~nm}$ ) between Ab-QDs and GONAP and thus hindering non-radiative energy transfer. We demonstrate that this simple -yet highly sensitive- platform represents a virtually universal immunosensing approach by using small-sized and big-sized targets as model analytes, those are, human-IgG protein and Escherichia coli bacteria. In addition, the assay was proved effective in real matrices analysis, including human serum, poultry meat and river water. GONAP opens the way to conceptually new paper-based devices for immunosensing, which are amenable to point of care applications and automated diagnostics.

\section{Introduction}

Immunoassays capitalize on the selectivity and sensitivity of antibody-antigen interactions so as to capture and detect analytes in biological or environmental samples. ${ }^{[1]}$ Being highly specific techniques, immunoassays are the most extensively used detection approaches for the analytical determination of clinically relevant biomarkers. ${ }^{[2,3]}$ They are also important drug screening platforms and prominent proteomic tools. ${ }^{[4,5]}$ Consequently, they are a corner-stone in diagnostics and biological research. In fact, there are different configurations (direct, indirect, sandwich, competitive) and various technologies exploiting immunoassays such as microarray, lateral flow and enzyme-linked immunosorbent assay. ${ }^{[1]}$ Nevertheless, they often require time-consuming labors (e.g. multiple washing steps) and/or at least two antibodies in charge of the capture and detection of the analyte, respectively. In addition, most of them are not particularly easy-to-use or amenable to portability. ${ }^{[6]}$ Given this paucity, the technological and scientific community is actively working on the development of cost-efficient and simple approaches facilitating innovative immunosensing approaches. ${ }^{[7-15]}$

We have previously reported bacterial cellulose nanopaper as an advantageous biosensing platform since it offers a myriad of outstanding properties, ${ }^{[16,17]}$ including environmental sustainability, biodegradability, excellent chemical-modification capabilities (so as to be functionalized), optical transparency and several other physicochemical properties (low density, hydrophilicity, high porosity, high flexibility, high surface area and high crystallinity). ${ }^{[18,19]}$ Moreover, we have been studying the interaction between photoexcited 


\section{WILEY-VCH}

quantum dots and graphene oxide (GO), offering innovative approaches in biosensing based on non-radiative energy transfer, which is highly efficient due to the high surface area and excellent photoluminescence-quenching nature exhibited by $\mathrm{GO},{ }^{[20]}$ even when compared with other carbon forms. ${ }^{[21]}$ Herein, we engineered a hydrophilic, porous and photoluminescence-quenching nanohybrid material made of graphene oxide-coated nanopaper (GONAP). Although the optical properties of GO have been exploited in several immunosensing systems, they often require both, a capture antibody and a detection antibody. ${ }^{[22,23]}$ GONAP represents an advantageous immunosensing platform that uses a single antibody and requires no-washing steps. This nanocomposite facilitates adsorption and quenching of photoluminecent quantum dots nanocrystals conjugated with antibodies (AbQDs), allowing a ready-to-use immunosensing platform. As the immunocomplex creation involves hydrogen bonding, electrostatic, hydrophobic and Van der Waals interactions, the complex antigen-Ab-QDs undergoes a desorption from GONAP surface upon immunocomplex formation and the photoluminescence is then recovered given that the antigen is anchored onto the GONAP surface by electrostatic, $\pi-\pi$ stacking and hydrogen bonding interactions. Specifically, given the moieties of GO, such as hydroxyl and carboxyl groups, and the hydroxyl groups of nanopaper, hydrogen bonding between GONAP and hydroxyl and amino groups presents in the analytes (or Ab-QDs) is also able to occur. These phenomena lead to a spacer (greater than c.a. $20 \mathrm{~nm}$ ) between Ab-QDs and GONAP, which avoids highly efficient non-radiative energy transfer. Thus, the fluorescence recovery is proportional to the analyte concentration. The operational concept of this immunosensing platform is depicted in Figure 1. To demonstrate that this immunosensing platform is technically sound for small-sized and big-sized targets detection, we employed human-IgG protein and Escherichia coli (E. coli) bacteria as model analytes, respectively. Additionally, we performed a series of assays in real matrices such as human serum, poultry meat and river water to prove the potential effectiveness of the approach in real sample analysis. 


\section{WILEY-VCH}

\section{GONAP biosensing platform}

Bacterial cellulose nanopaper (BC, a film of nanocellulose) synthesized by Acetobacter xylinum was employed in the proposed immunosensing platform. $\mathrm{BC}$ has been previously characterized in terms of average fiber diameter (c.a. $45 \pm 10 \mathrm{~nm})$, fiber length $(>10 \mu \mathrm{m})$, crystallinity $(\sim 82 \%)$, crystallite size $(\sim 6.3 \mathrm{~nm})$, average tensile strength $(\sim 345 \mathrm{MPa})$, Young's modulus $(\sim 17.3 \mathrm{GPa})$ and strain-at-break $(\sim 7 \%) \cdot{ }^{[16]}$ A water-based dispersion of single layer GO sheets with average lateral dimension range of $\sim 500 \mathrm{~nm}$ and $\mathrm{C} / \mathrm{O}$ ratio about one unit (supplier's data) was exploited to build the GONAP nanocomposite. As BC exhibits hydroxyl groups onto the surface and GO also has hydroxyl groups onto the basal plane, they can be easily coupled via hydrogen bonding (see experimental section). Streptavidindecorated CdSe@ZnS QDs with an average size $\sim 14 \pm 2$ nm and a maximum emission wavelength at $\sim 665 \mathrm{~nm}$ were employed as photoluminecent agent in the proposed immunosensing platform. Scanning electron microscopy micrographs of bare BC, GONAP and Ab-QDs-GONAP are shown in Figure 2, respectively.

Various concentrations of GO decorating $\mathrm{BC}$ were evaluated and compared with bare $\mathrm{BC}$ in order to select the most efficient photoluminescence-quenching concentration judiciously. Herein, $150 \mu \mathrm{g} \mathrm{mL}^{-1}$ of $\mathrm{GO}$ in milliQ water was selected as the optimum concentration and the most appropriate for the immunosensing platform (see supplementary Figure $\mathbf{S 1}$ and $\mathbf{S 2}$ in the supporting information), which achieved the maximum quenching efficiency (around $50 \%$ ) when compared with bare BC. Additionally, the concentration of QDs and anti-E. coli antibody and the incubation time for the immunoreaction were carefully selected based on the most sensitive response, taking the analysis of the blank sample as reference. It was found that the optimum concentrations of QDs and $\mathrm{Ab}$ are $100 \mathrm{nM}$ and $0.9 \mathrm{mg} \mathrm{mL}^{-1}$, respectively.

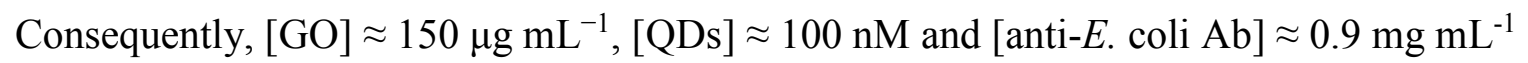
were employed for sensitive detection of foodborne pathogen (E. coli O157:H7). Moreover, 


\section{WILEY-VCH}

the optimum incubation time was 30 min for capturing the target bacteria by the specific $\mathrm{Ab}$. The same aforementioned optimization procedures were carried out for protein detection, whereas the optimum concentrations were $c a .100 \mu \mathrm{mL}^{-1}, 100 \mathrm{nM}$, and $0.2 \mathrm{mg} \mathrm{mL}^{-1}$ for $\mathrm{GO}$, QDs and anti-human IgG Ab, respectively for protein detection, while an optimum incubation period of $2 \mathrm{~h}$ was found the most appropriate for protein detection (see supplementary Figure S5). It is well known that the suitable incubation time for any immunoreaction strongly depends on the analyte size, ${ }^{[24]}$ thus there is a significant difference between $E$. coli and protein detection in this parameter $(E$. coli size $\approx 0.5 \times 1.5-2 \mu \mathrm{m}$, human IgG size $\approx 12 \mathrm{~nm})$. Although the size of these analytes is completely different, the biosensing mechanism is driven by the same aforementioned principle that eventually leads to a spacer between photoexcited QDs and GONAP (greater than c.a. $20 \mathrm{~nm}$ ), hindering a highly efficient nonradiative energy transfer phenomenon. Thus, the proposed biosensing system is able to detect both small-sized and big-sized analytes as demonstrated below.

\subsection{GONAP for pathogen detection}

The performance of the proposed immunosensing platform as a pathogen detection device was evaluated by using ten-fold serial concentrations of $E$. coli $\mathrm{O} 157: \mathrm{H} 7$ (10 to $10^{6} \mathrm{CFU}$ $\mathrm{mL}^{-1}$ ) in a standard buffer. Blank sample (buffer containing zero bacteria) was studied to distinguish between the presence and the absence of the target analyte. The photoluminescence intensity ratios $\left(\mathrm{F}_{1} / \mathrm{F}_{0}\right)$ of the test and the blank spots were estimated in dimensionless units by dividing the final photoluminescence intensity $\left(\mathrm{F}_{1}\right)$ into the initial photoluminescence intensity $\left(\mathrm{F}_{0}\right)$ of the same GONAP spot, which determine the presence or absence of the target pathogen. Furthermore, the $\mathrm{F}_{1} / \mathrm{F}_{0}$ ratio allows for the measurement of tiny amounts of the analyte circumventing analytical problems due to the original intensity of $\mathrm{F}_{0}$, which can be considered the background signal. Given the operational concept of the immunosensing platform, the photoluminescence of the test spots is expected to increase upon 


\section{WILEY-VCH}

addition of the pathogen, whereas that of the blank spots is expected to be relatively constant or decrease slightly due to the removal of the excess of some Ab-QD complexes after the contact with the liquid sample. Figure 3a shows how the $F_{1} / F_{0}$ ratio of the analyzed blank sample was around 0.8 , while serial dilutions of $E$. coli obtained a $F_{1} / F_{0}$ ratio greater than this value. The proposed immunosensing platform showed a highly sensitive response to the presence of the target bacteria with a wide detection range, from 10 to $10^{6} \mathrm{CFU} \mathrm{mL}^{-1}$, where the $\mathrm{F}_{1} / \mathrm{F}_{0}$ ratio increased gradually with $E$. coli concentration at the range from 10 to $10^{5} \mathrm{CFU}$ $\mathrm{mL}^{-1}$ with a full saturation of the system at $10^{6} \mathrm{CFU} \mathrm{mL}^{-1}$. As experimental evidences, Figure $3 \mathrm{~b}$ shows images of the photoluminescent performance of GONAP immunosensing platform targeting E. coli. and Figure 3c displays a SEM micrograph of the platform after adding the target bacteria. Moreover, from that logarithmic response, the estimated detection limit of $E$.

coli in standard buffer was about $55 \mathrm{CFU} \mathrm{mL}^{-1}$, which has been calculated by the mean value $\mathrm{F}_{1} / \mathrm{F}_{0}$ ratio of the blank plus 3 times its standard deviation, see Supplementary Figure 10A (threshold line).

In order to investigate the effect of washing steps on GONAP immunosensing platform, a series of assays was carried out via GONAP immunosensing platform and washing steps were performed using $100 \mu \mathrm{L}$ of PBST followed by $100 \mu \mathrm{L}$ milli-Q water. After discarding the washing solution, a fluctuating response in the $\mathrm{F}_{1} / \mathrm{F}_{0}$ ratio with serial $E$. coli concentrations has been observed. This could be attributed to the weak attaching forces between GONAP and the complex antigen-Ab-QDs. ${ }^{[25]}$ This fluctuating response is shown in supplementary Figure S4. Importantly, we discovered that the overall optimal performance of the proposed immnosensing platform does not require washing steps.

\subsubsection{GONAP specificity in pathogen detection}




\section{WILEY-VCH}

We also explored the specificity of GONAP immunosensing platform targeting $E$. coli in the presence of another non-target bacterial strain form the same "Enterobacteriaceae family". Salmonella typhimurium was selected as a non-specific pathogen for conducting this experiment. Different concentrations of the target and non-target bacteria were simultaneously analyzed in standard buffer in order to assess the specificity of the developed assay as follows; a) blank standard buffer, b) low concentration of $E$. coli $\left(10^{2} \mathrm{CFU} \mathrm{mL} \mathrm{m}^{-1}\right)$, c) high concentration of $E$. coli $\left(10^{5} \mathrm{CFU} \mathrm{mL}^{-1}\right)$, d) high concentration of $S$. typhimurium $\left(10^{5} \mathrm{CFU}\right.$ $\left.\mathrm{mL}^{-1}\right)$, e) a mixture of high concentration of $E$. coli $\left(10^{5} \mathrm{CFU} \mathrm{mL} \mathrm{m}^{-1}\right)$ and low concentration of $S$. typhimurium $\left(10^{2} \mathrm{CFU} \mathrm{mL} \mathrm{m}^{-1}\right)$ and $\left.\mathrm{f}\right)$ a mixture of high concentration of $S$. typhimurium $\left(10^{5}\right.$ $\left.\mathrm{CFU} \mathrm{mL} \mathrm{m}^{-1}\right)$ and low concentration of $E$. coli $\left(10^{2} \mathrm{CFU} \mathrm{mL}^{-1}\right)$. It was found, as illustrated in Figure $3 \mathrm{~d}$, that the $\mathrm{F}_{1} / \mathrm{F}_{0}$ ratio of the non-target pathogen ( $S$. typhimurium) even at high concentration was below the threshold of the limit of detection limit (LOD) and very similar to blank one. Additionally, the presence of the non-target pathogen in the same media with the target one (E. coli) does not affect the response of the immunoassay; since the response produced by a mixture of $\left[E\right.$. coli $\left(10^{2} \mathrm{CFU} \mathrm{mL} \mathrm{m}^{-1}\right)+S$. typhimurium $\left.\left(10^{5} \mathrm{CFU} \mathrm{mL}^{-1}\right)\right]$ was very similar to that of $E$. coli $\left(10^{2} \mathrm{CFU} \mathrm{mL} \mathrm{m}^{-1}\right)$ alone, likewise, the response of a mixture $[E$. coli $\left(10^{5} \mathrm{CFU} \mathrm{mL} \mathrm{mL}^{-1}\right)+S$. typhimurium $\left.\left(10^{2} \mathrm{CFU} \mathrm{mL}^{-1}\right)\right]$ was very close to that of $E$. coli $\left(10^{5}\right.$ CFU mL $\mathrm{m}^{-1}$ ) alone. These results indicate the high specificity and selectivity of the developed immunoassay even in the presence of other competing non-specific bacteria.

\subsubsection{GONAP for pathogen detection in real samples}

Although the application of any developed assay in buffer solution is very important for optimization, the analysis in real samples with minimal sample preparation is crucial in emergent biosensing platforms. ${ }^{[7]}$ Therefore, serial concentrations of $E$. coli O157:H7 were inoculated in poultry meat and river water to be assayed by the proposed GONAP-based pathogen detection platform. Blank solutions of both poultry meat extract and river water were used as a negative control in this experiment. As shown in Supplementary Figure S5, 


\section{WILEY-VCH}

the $F_{1} / F_{0}$ ratios of the blank solutions of poultry meat extract and river water were around 0.7 and 0.8 , respectively. While the presence of the target bacteria increases the $F_{1} / F_{0}$ ratio to higher values. The obtained results illustrated in Supplementary Figure S5A-B show that the proposed pathogen detection platform has a highly sensitive response to the presence of $E$. coli in complex matrices of poultry meat and river water at wide detection ranges accounted for 50 to $1.5 \times 10^{5} \mathrm{CFU} \mathrm{g}^{-1}$ and 50 to $10^{5} \mathrm{CFU} \mathrm{mL}^{-1}$, respectively. Whereas, the $\mathrm{F}_{1} / \mathrm{F}_{0}$ ratios raised gradually with increasing bacterial concentrations with logarithmic responses at the ranges 50 to $1.5 \times 10^{4} \mathrm{CFU} \mathrm{g}^{-1}$ and 50 to $10^{4} \mathrm{CFU} \mathrm{mL}^{-1}$ in poultry meat and river water, respectively (Supplementary Figure S5). From these logarithmic responses, it was estimated that the limit of detection of $E$. coli in poultry meat and river water are 65 and $70 \mathrm{CFU} g$ or $\mathrm{mL}^{-1}$, respectively. These relatively low limits of detection in real samples without broth enrichment indicate the capability of $E$. coli detection in real food and water samples at levels $<1 \mathrm{CFU} \mathrm{g}{ }^{-1}$ and $1 \mathrm{CFU} \mathrm{mL}^{-1}$ respectively after $c a .2$ hours of broth incubation. Although there was a slight influence by the matrix of real samples due to the effect of the microenvironment changes (the local viscosity, $\mathrm{pH}$, ionic strength, polarity and hydrogenbonding capability of the matrix) on the photoluminescence of QDs, ${ }^{[26]}$ it does not affect the feasibility of the assay in real samples and confirms the possibility of using this novel immunoassay for pathogen detection in other complex real samples. As detailed in the Supporting Information, recovery tests were performed in order to investigate the accuracy and the performance of the developed immunoassay in complex matrices and standard buffer. These results confirming an acceptable accuracy level of the proposed system are shown in Table 1.

\subsection{GONAP for protein detection}

In addition, we explored the overall performance of GONAP immunosensing platform for the detection of a human protein. Human IgG has been employed as a model protein. Firstly, a 


\section{WILEY-VCH}

polyclonal anti-human $\operatorname{IgG}$ antibody (pAb) was used for the immunoassay. Several concentrations of human IgG ranging from 3.125 to $50 \mathrm{ng} \mathrm{mL}^{-1}$ in standard buffer were investigated (under optimized condition, supplementary Figure S3). As shown in supplementary Figure $\mathbf{S 9}$, the $\mathrm{F}_{1} / \mathrm{F}_{0}$ ratio of the blank buffer was around 0.9 units, while the presence of the target analyte (IgG) obtained greater values due to the aforementioned operational principle of the proposed immunosensing system. A detection range from 3.125 to $25 \mathrm{ng} \mathrm{mL} \mathrm{L}^{-1}$ was obtained, (Supplementary Figure S9A). A scanned photo of GONAP before and after various amounts of $\operatorname{IgG}$ (from top and downward; 3.125, 6.25, 12.5 and $25 \mathrm{ng} \mathrm{mL}^{-1}$ ) presented that the photoluminescent intensity is correlational with the amount of protein, see Supplementary Figure S9B. From that logarithmic relation, a limit of detection accounted for $1.91 \mathrm{ng} \mathrm{mL}^{-1}$ was obtained (Supplementary Figure S11a).

To investigate whether this innovative immunoassay can only be accomplished by integrating polyclonal antibodies or not, a monoclonal antibody targeting human $\operatorname{IgG}(\mathrm{mAb})$ was also employed. Interestingly, it was found that GONAP immunosensing platform is also able to operate using monoclonal antibodies. In fact, $\mathrm{mAb}$ provided greater fluorescence intensities than those obtained using polyclonal antibodies when both were compared using human $\operatorname{IgG}$ concentration of $3.125 \mathrm{ng} \mathrm{mL}^{-1}$ (Supplementary Figure S11d). For human IgG detection using $\mathrm{mAb}$, the detection range was $195 \mathrm{pg} \mathrm{mL}^{-1}$ to $3.125 \mathrm{ng} \mathrm{mL}^{-1}$ (Figure 4a), and provided a lower limit of detection than that of $\mathrm{pAb}$, accounted for $1.60 \mathrm{ng} \mathrm{mL}^{-1}$, as calculated from the logarithmic response in Supplementary Figure S1 1b. Importantly, pAb are expected to perform a sandwich-like immunocomplex due to its ability to bind multiple sites of the antigen, whereas $\mathrm{mAb}$ cannot perform a sandwich-like configuration due to its ability to bind a single site of the antigen. Hence, these results suggest both, that the complex antigen-AbQD is likely to be anchored by the antigen side and that GONAP is also able to anchor sandwich-like immunocomplexes (supplementary Figure S6), enforcing the virtually universal operational principle of GONAP immunosensing platform. Moreover, scanning 


\section{WILEY-VCH}

electron microcopy revealed that $\mathrm{mAb}$ promotes a higher population density of complexes antigen-Ab-QD upon analyte addition (Figure 4d) when compared to that promoted by using $\mathrm{pAb}$ (Figure 4c). This observation clarifies the high sensitivity obtained by using mAb. The selectivity study of the proposed GONAP-based immunoassay for protein detection was also investigated in the presence of non-specific immunoglobulin type and using pAb (it should be remarked that polyclonal antibodies are often less specific than monoclonal antibodies). These experiments are described in the Supporting Information, whose results indicate the high specificity of the developed immunoassay using pAb even in the presence of other competing non-specific type of immunoglobulin (supplementary Figure S7). Likewise, we successfully explored the efficiency of the protein sensing platform in complex matrixes by screening different concentrations of human $\operatorname{IgG}(\mathrm{HIgG})$ in human serum (supplementary

\section{Figure S8).}

\subsubsection{GONAP for protein detection in real samples}

Moreover, in order to compare the performance of the developed immunoassay in real samples and standard buffer, spike and recovery tests were done using human immunoglobulin-depleted serum as a real matrix. Three concentrations of human $\operatorname{IgG}$ within the respective detection range were spiked in human immunoglobulin depleted serum samples, and then the recovery percentages from human serum were estimated and compared with those of standard buffer. It was found that the recoveries of human IgG from human serum ranged from 93 to 98\%, as listed in Table 2. These recovery percentages indicate that the complex matrix of human serum does not affect the reliability of the proposed immunoassay and confirm the possibility of its application in real sample analysis.

\section{Conclusion}

Taking advantage of the hydrophilic, porous and photoluminescence-quenching character of GONAP, we developed an advantageous and highly transformative immunosensing platform 


\section{WILEY-VCH}

requiring no-washing steps and exploiting a single antibody. The immonosensing mechanism is triggered by an immunoreaction leading to both, desorption of previously anchored AbQDs and attachment of the complex antigen-Ab-QD. This configures a spacer $(>\sim 20 \mathrm{~nm})$ between GONAP and the Ab-QDs, disrupting highly efficient non-radiative energy transfer. Fast (30 min), highly sensitive and selective detection and quantification of a pathogen $(E$. coli) have been recorded at limits of detection accounted for $c a .55,65$ and $70 \mathrm{CFU} \mathrm{mL} \mathrm{m}^{-1}$ or g-

${ }^{1}$ in standard buffer, poultry meat and river water, respectively, without previous broth

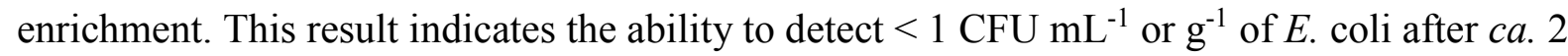
hours of sample-broth enrichment. Moreover, the proposed device showed a quick (120 min) and sensitive detection of human protein at a detection limit of for $1.60 \mathrm{ng} \mathrm{mL} \mathrm{m}^{-1}$. In addition, this innovative immunosensing platform is able to show an acceptable level of accuracy (recovery values between 93 and 98\%). Although the specificity and sensitivity (in terms of percentage of false positive/negatives, respectively) of this approach has not been determined in the present stage of this research, the successful application of this immunoassay in real matrices analysis opens up innovative capabilities in food, environmental and biological samples analysis. Additionally, this paper-based platform is easy-to-use, cost-effective, and suitable for portability, point of care applications, automated devices, and multi-analyte detection as well.

\section{Experimental Section}

All commercial reagents were of analytical grade and handled according to the material safety data sheets suggested by the suppliers. Bacterial cellulose nanopaper $(\mathrm{BC})$ was purchased from Nanonovin Polymer Co. (Mazandaran, Iran). Graphene oxide (GO) was purchased from Angstron Materials (Dayton, OH, U.S.A.). Poly-L-lysine coated glass slides (Cat.No. 222471) were purchased from Polysciences Europe GmbH (Hirschberg an der Bergstrasse, Germany). Anti-Escherichia coli antibody (biotin) (pAb, ab68451), sheep anti-human IgG 


\section{WILEY-VCH}

H\&L (biotin) and Mouse monoclonal H2 anti-human IgG Fc (biotin) (mAb, ab99766) were obtained from Abcam (Cambridge, U.K.), and streptavidin-quantum dot 655 was from Life Technologies (Carlsbad, CA, USA). Phosphate buffered saline (PBS) tablet (P4417), bovine serum albumin (BSA), and Tween-20 were purchased from Sigma-Aldrich (Madrid, Spain). Escherichia coli O157:H7 (CECT 4783, E. coli) and Salmonella enterica subsp. enterica serovar typhimurium LT2 (CECT 722T, S. typhimurium) strains were obtained from the Colección Española de Cultivos Tipo (CECT, Valencia, Spain). IgG and IgA from human serum were purchased from Sigma-Aldrich (Madrid, Spain). Human immunoglobulin IgG/ IgA/ IgM/ IgE depleted serum was purchased from Celprogen (Torrance, CA, USA). PBS (10 mM, pH 7.4) with $0.5 \%(\mathrm{v} / \mathrm{v})$ Tween-20 containing $1 \%$ of BSA fraction $\mathrm{V}(\mathrm{w} / \mathrm{v})$ was employed as standard buffer. All aqueous solutions were freshly prepared in ultrapure water

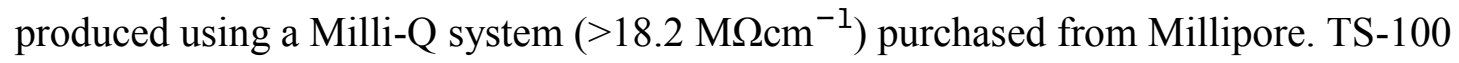
Thermo-Shaker (Biosan, Riga, Latvia) was used as the stirrer for modification of QDs with antibodies. An AlphaScan ${ }^{\mathrm{TM}} 3.0$ microarray scanner (San Leandro, CA, USA) was used to record the photoluminescence images on GONAP surface. A JP Selecta 2000210 oven (JP Selecta s.a., Barcelona, Spain) was used for drying graphene oxide nanocomposites. Scanning electron microscopy (SEM) was performed through a Magellan 400L SEM High Resolution SEM (FEI, Hillsboro, OR, USA).

Synthesis of GONAP. GO was integrated into the BC nanonetwork via hydrogen bonding by taking advantage of the presence of hydroxyl groups exhibited by both BC and GO. To this end, nine pieces of previously sterilized wet BC (approx. size $0.25 \times 0.25 \times 0.1 \mathrm{~cm}^{3}$ ) were washed in $100 \mathrm{~mL}$ of hot milliQ water at $60^{\circ} \mathrm{C}$ for 30 min under vigorous stirring. Consequently, the water was discarded and $100 \mathrm{~mL}$ of graphene oxide suspension $(150 \mu \mathrm{g}$ $\mathrm{mL}^{-1}$ ) was added to the cellulose nanopaper (see detailed optimization procedure of GO concentration in the supplementary material) and incubated at $90^{\circ} \mathrm{C}$ for $2 \mathrm{~h}$ with vigorous stirring. After that, GONAP was separated from the GO suspension and washed 5 times with 


\section{WILEY-VCH}

milliQ water, which removes unbound $\mathrm{GO}$ and ensures a homogeneous distribution of the

$\mathrm{GO}$ embedded in $\mathrm{BC}$. Finally, the composites were kept to dry in a hot air oven at $50^{\circ} \mathrm{C}$ for 30

min. The color change of $\mathrm{BC}$ from colorless to dark brown confirms the synthesis of GONAP. Then, the dried composites were kept at room temperature under dark conditions before being used in the immunoassay. SEM was used to characterize and confirm the successful synthesis of the composite.

Conjugation of $Q D s$ with antibodies $(A b)$. For pathogen detection, QDs were mixed with antiE.coli $\mathrm{Ab}$ in a standard buffer to form final concentrations of $100 \mathrm{nM}$ for QDs and $900 \mu \mathrm{g}$ $\mathrm{mL}^{-1}$ for $\mathrm{Ab}$. While for protein detection, QDs were mixed with anti-human IgG $\mathrm{Ab}$ in the standard buffer to reach final concentrations of $100 \mathrm{nM}$ for QDs and $200 \mu \mathrm{g} \mathrm{mL}^{-1}$ for $\mathrm{Ab}$. Subsequently, the conjugation process was carried out by continuous shaking at $650 \mathrm{rpm}$, and $4^{\circ} \mathrm{C}$ for $30 \mathrm{~min}$ (see detailed optimization procedure of QDs concentration and the conjugation process in the Supporting Information, Figures S1, S2 and S3).

Bacterial Strains and Inocula Preparation. Freeze-dried cultures of E. coli O157:H7 and Salmonella typhimurium were revived in Tryptone Soy Broth (TSB, Oxoid Ltd., UK) and incubated for $24 \mathrm{~h}$ at $37^{\circ} \mathrm{C}$, then transferred onto Tryptone Soy Agar plates (TSA, Oxoid Ltd., UK). Stock cultures of both strains were prepared on Tryptone Soy Agar slopes for future use. Afterwards, bacterial cell suspensions were prepared directly in sterile PBST and river water, using bacterial colonies from the plates, during the logarithmic phase, to obtain a bacterial load of $1.5 \times 10^{8} \mathrm{CFU} \mathrm{mL}^{-1}$ according to McFarland standards ${ }^{[27]}$ using Densimat densitometer (Biomerieux, Brazil). Subsequently, ten-fold decimal bacterial dilutions (10 to $10^{8} \mathrm{CFU} \mathrm{mL} \mathrm{m}^{-1}$ ) were prepared from the original one. Finally, heat killing of the inocula was performed by placing the inoculated tubes in a water bath at $90^{\circ} \mathrm{C}$ for $15 \mathrm{~min}$ to stop bacterial replication. While in case of poultry meat, a tube of heat-killed bacteria $\left(1.5 \times 10^{8} \mathrm{CFU} \mathrm{mL}{ }^{-1}\right)$ in sterile PBST was used to prepare ten-fold decimal dilutions in poultry extract. The prepared inocula were stored at $4{ }^{\circ} \mathrm{C}$ until being used. 


\section{WILEY-VCH}

Preparation of poultry meat extract: chicken meat fillets were obtained from a local retail market in Barcelona and analyzed by standard culturing method for the presence of $E$. coli ${ }^{[28]}$, and only negative samples were selected to be inoculated with bacteria. Twenty-five grams of E. coli-free poultry meat were homogenized with $225 \mathrm{~mL}$ of sterile PBS in a sterile bag using a stomacher (Lab Blender 400, Seward, UK) for $3 \mathrm{~min}$. Then the homogenate was clarified by filtration using Whatman filter paper, grade 41 (pore size: 20-25 $\mu \mathrm{m}$ ) to remove large particles, and finally the filtrate was used as a diluent for preparation of different bacterial inocula.

Preparation of GONAP immunosensing platform. A punching tool was used to cut the dried GO-BC composites into small rounded spots (Diameter $\approx 0.6 \mathrm{~cm}$ ), and then these spots were placed onto a poly-L-lysine slide. Consequently, $1.5 \mu \mathrm{L}$ of the previously prepared QDs- $\mathrm{Ab}$ conjugate was dropped on each GONAP spot, and left to dry at room temperature. The initial photoluminescence intensity $\left(\mathrm{F}_{0}\right)$ of these spots was measured using a microarray scanner. A silicone gasket was used per each slide to separate each spot/assay.

Using GONAP immunosensing platform for E. coli detection in a standard buffer. $100 \mu \mathrm{L}$ of each dilution of the previously prepared suspensions of $E$. coli O157:H7 in standard buffer

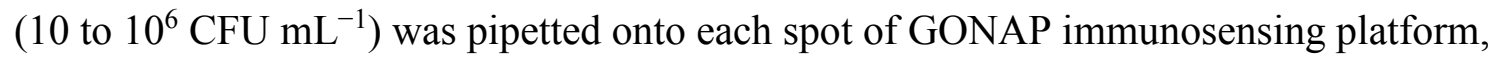
which were placed on the poly-L-lysine slide masked with silicone gasket. In parallel, control spots were prepared using standard buffer free of $E$. coli. Three parallel experiments analyzing the same sample were carried out to ensure repeatability. Then the mixture was incubated at room temperature for $30 \mathrm{~min}$. Afterward, bacterial suspensions were discarded and the test and control spots were left to dry at room temperature before reading the final intensity of the photoluminescence $\left(\mathrm{F}_{1}\right)$ using the microarray scanner. ImageJ 1.50i (Wayne Rasband, National Institutes of Health, Maryland, USA) was used to analyze both initial and final photoluminescence intensities to calculate the intensity ratio $\left(\mathrm{F}_{1} / \mathrm{F}_{0}\right)$. Limit of detection (LOD) of the developed immunoassay was estimated by calculating the average $\mathrm{F}_{1} / \mathrm{F}_{0}$ of 


\section{WILEY-VCH}

blank samples plus three times the standard deviation. The specificity of the assay was evaluated using Salmonella typhimurium as non-specific bacteria (separately and in the presence of $E$. coli O157:H7).

Validating GONAP immunosensing platform for E. coli detection in real matrices. The performance of the developed immunosensing platform in bacteria detection was evaluated in complex matrices using poultry meat and river water as model samples. The same aforementioned procedure carried out for $E$. coli inoculated in standard buffer was applied for previously prepared ten-fold serial concentrations of $E$. coli $\mathrm{O} 157: \mathrm{H} 7$ inocula in poultry meat and river water; however, the concentration of QDs was increased to $120 \mathrm{nM}$ in case of river water. LOD in real samples was estimated by the same above mentioned method in standard buffer.

To assure whether the performance is affected by the difference between the buffer used to prepare the standard curve and the real sample matrix or not, spike and recovery experiment was conducted to assess the precision of the developed immunosensing platform in complex sample types. This experiment was conducted by spiking $10^{2}, 10^{3}$ and $10^{4} \mathrm{CFU} \mathrm{mL}^{-1}$ or $\mathrm{g}$ of $E$.coli $\mathrm{O} 157: \mathrm{H} 7$ in standard buffer, poultry meat and river water (three replicates for each bacterial concentration in each sample) and the recovery percentages of the bacteria from real samples (poultry meat and river water) were calculated as comparing with the standard buffer. Using GONAP immunosensing platform for protein detection in standard buffer. The aforementioned procedure of $E$. coli detection was adapted in case of protein (human IgG) detection. Briefly, human IgG was prepared at different concentrations in the standard buffer (3.125 to $100 \mathrm{ng} \mathrm{mL}^{-1}$ ) and stored in the fridge at $4^{\circ} \mathrm{C}$ until use. $100 \mu \mathrm{L}$ of the analyte suspensions were added on the previously prepared spots of GONAP immunosensing platform for human IgG. After incubation for $2 \mathrm{~h}$ at room temperature, the analyte suspension was discarded and the spots were left to dry at room temperature before reading the final photoluminescence intensity using a microarray scanner. Afterwards, the analysis of the 


\section{WILEY-VCH}

images and calculation of the LOD of IgG were done by the same above-mentioned methods used in $E$. coli detection. The specificity of the assay was evaluated using human IgA as a non-target protein (separately and in a mixture with human $\operatorname{IgG}$ ).

Validating GONAP immunosensing platform for protein detection in human serum. The performance of the developed immunosensing platform for protein detection was evaluated in complex real matrices using human immunoglobulin-depleted serum as a real matrix. The same aforementioned procedure carried out with human $\operatorname{IgG}$ inoculated in standard buffer was conducted for various concentrations of human $\operatorname{IgG}\left(7\right.$ to $\left.700 \mathrm{ng} \mathrm{mL}^{-1}\right)$ in human immunoglobulin-depleted serum. The LOD of Human IgG in human serum was estimated by the same abovementioned method in $E$. coli detection. Similar to $E$. coli detection procedures, a spike and recovery test was conducted for $\operatorname{IgG}$ by spiking $6.25,12.5$ and $25 \mathrm{ng} \mathrm{mL}^{-1}$ of $\operatorname{IgG}$ in both standard buffer and human immunoglobulin-depleted serum (at least 3 replicates for each protein concentration) and the recovery percentages of protein from human serum were calculated as comparing with standard buffer.

\section{Supporting Information}

Supporting Information is available from the Wiley Online Library or from the author.

\section{Acknowledgements}

The Nanobiosensors and Bioelectronics Group acknowledges the support from H2020-EU (INTCATCH Project, Ref. 689341) and the Generalitat de Catalunya (Grant 2014 SGR 260). ICN2 acknowledges support from the Severo Ochoa Program (MINECO, Grant SEV-20130295). N. C. acknowledges the Royal Golden Jubilee Project of the Thailand Research Fund, in cooperation with the King Mongkut's University of Technology Thonburi for the Ph.D. scholarship (PhD/0109/2553).

Received: ((will be filled in by the editorial staff))

Revised: ((will be filled in by the editorial staff)) Published online: ((will be filled in by the editorial staff))

\section{References}

[1] D. Wild, In The Immunoassay Handbook (Fourth Edition); Elsevier: Oxford, 2013; pp. 7-10. 


\section{WILEY-VCH}

[2] M. C. Brown, In Lateral Flow Immunoassay; Wong, R.; Tse, H., Eds.; Humana Press: Totowa, NJ, 2009; pp. 1-16.

[3] Y. Wang, R. Vaidyanathan, M. J. A. Shiddiky, M. Trau, ACS Nano 2015, 9, 6354.

[4] I. Wright, J. E. Van Eyk, Clin. Chem. 2016, 63, 245.

[5] A. G. Paulovich, J. R. Whiteaker, Nat Biotech 2016, 34, 1033.

[6] B. Berg, B. Cortazar, D. Tseng, H. Ozkan, S. Feng, Q. Wei, R. Y.-L. Chan, J. Burbano, Q. Farooqui, M. Lewinski, D. Di Carlo, O. B. Garner, A. Ozcan, ACS Nano 2015, 9, 7857.

[7] A. P. F. Turner, Chem. Soc. Rev. 2013, 42, 3184.

[8] R. de la Rica, M. M. Stevens, Nat. Nanotechnol. 2012, 7, 821.

[9] Y. Song, W. Wei, X. Qu, Adv. Mater. 2011, 23, 4215.

[10] Y. Zhang, Y. Guo, Y. Xianyu, W. Chen, Y. Zhao, X. Jiang, Adv. Mater. 2013, 25, 3802.

[11] E. Morales-Narváez, L. Baptista-Pires, A. Zamora-Gálvez, A. Merkoçi, Adv. Mater. 2017, 29, n/a.

[12] E. Waltz, Nat Biotech 2017, 35, 11.

[13] K. Yamada, T. G. Henares, K. Suzuki, D. Citterio, Angew. Chem. Int. Ed. 2015, 54, 5294.

[14] C. S. Jeon, I. Hwang, T. D. Chung, Adv. Funct. Mater. 2013, 23, 1484.

[15] Y. Zhu, K. Kekalo, C. NDong, Y.-Y. Huang, F. Shubitidze, K. E. Griswold, I. Baker, J. X. J. Zhang, Adv. Funct. Mater. 2016, 26, 3953.

[16] E. Morales-Narváez, H. Golmohammadi, T. Naghdi, H. Yousefi, U. Kostiv, D. Horák, N. Pourreza, A. Merkoçi, ACS Nano 2015, 9, 7296.

[17] B. Heli, E. Morales-Narváez, H. Golmohammadi, A. Ajji, A. Merkoçi, Nanoscale 2016, 8, 7984.

[18] D. Klemm, F. Kramer, S. Moritz, T. Lindström, M. Ankerfors, D. Gray, A. Dorris, Angew. Chem. Int. Ed. 2011, 50, 5438.

[19] H. Golmohammadi, E. Morales-Narváez, T. Naghdi, A. Merkoçi, Chem. Mater. 2017. DOI: 10.1021/acs.chemmater.7b01170

[20] E. Morales-Narváez, A.-R. Hassan, A. Merkoçi, Angew. Chem. Int. Ed. 2013, 52, 13779.

[21] E. Morales-Narváez, B. Pérez-López, L. B. Pires, A. Merkoçi, Carbon 2012, 50, 2987.

[22] M. Liu, H. Zhao, X. Quan, S. Chen, X. Fan, Chem. Commun. 2010, 46, 7909.

[23] J. H. T. Luong, S. K. Vashist, 2D Mater. Biosens. Bioelectron. 2017, 89, Part 1, 293.

[24] E. P. Diamandis, T. K. Christopoulos, Immunoassay; Academic Press, 1996.

[25] J.-L. Chen, X.-P. Yan, K. Meng, S.-F. Wang, Anal. Chem. 2011, 83, 8787.

[26] U. Resch-Genger, M. Grabolle, S. Cavaliere-Jaricot, R. Nitschke, T. Nann, Nat. Methods 2008, 5, 763.

[27] J. McFARLAND, J. Am. Med. Assoc. 1907, XLIX, 1176.

[28] ISO 7251:2005 - Microbiology of food and animal feeding stuffs -- Horizontal method for the detection and enumeration of presumptive Escherichia coli -- Most probable number technique. 


\section{WILEY-VCH}

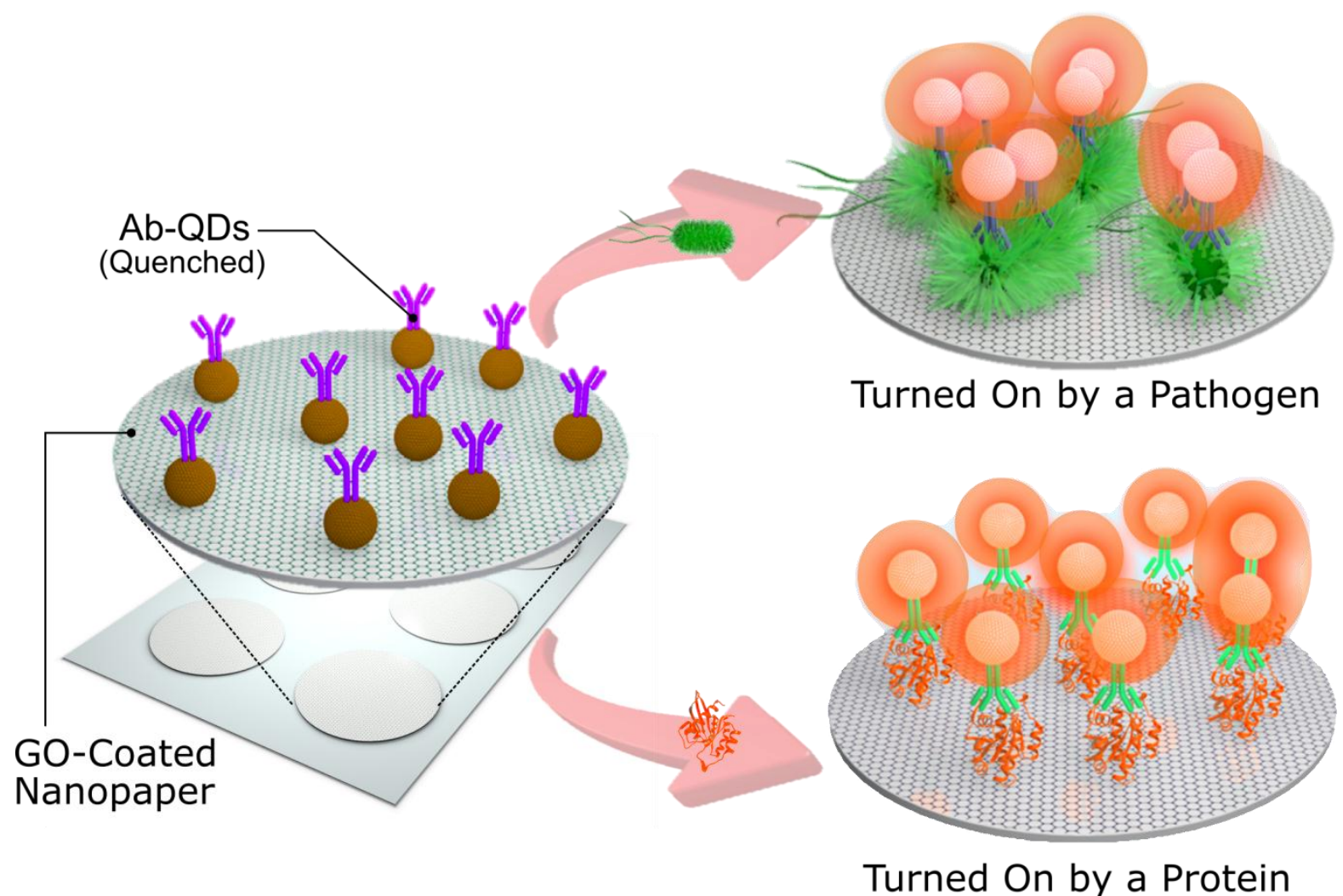

Figure 1. Operational concept of the immunosening approach (schematic representation, not to scale). The hydrophilic, porous and photoluminescence-quenching character of GONAP allows for the adsorption and quenching of Ab-QDs, whereas photoluminescence recovery is triggered by the immunocomplex formation phenomenon, which involves a series of forces and interactions detaching the antigen-Ab-QD complex. Nevertheless, the antigen is then attached onto GONAP surface working as spacer between GONAP and Ab-QDs and hindering highly efficient non-radiative energy transfer. The immunosensing platform can be turned "On" by either big-sized analytes (pathogens) or small-sized analytes (proteins).
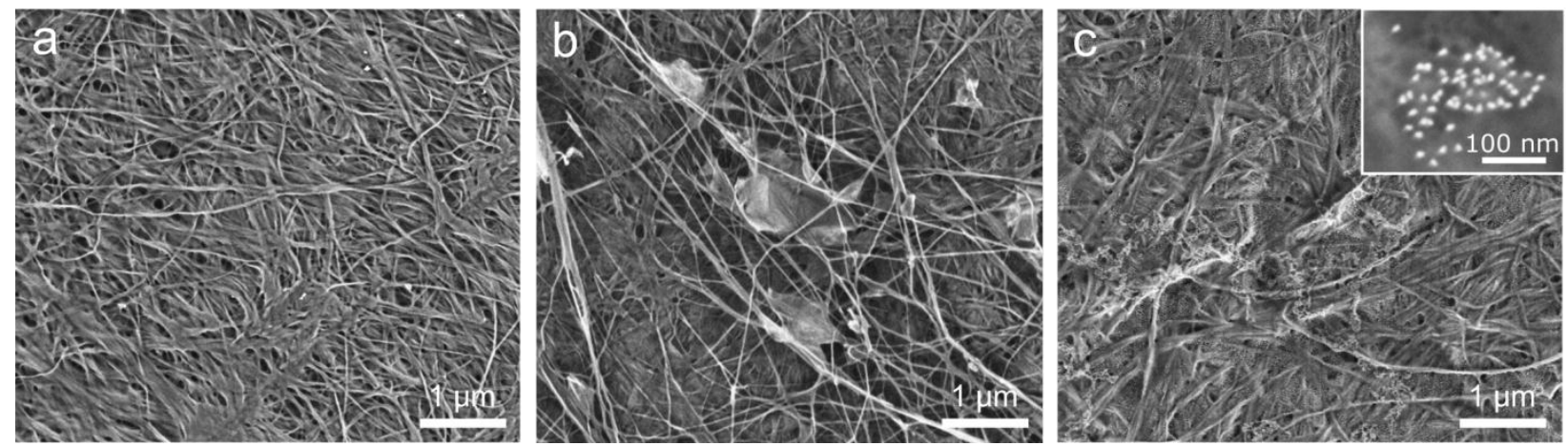

Figure 2. Scanning-electron micrographs of GONAP platform. a. Bare bacterial cellulose nanopaper. b. GONAP. c. Ab-QDs on GONAP. 

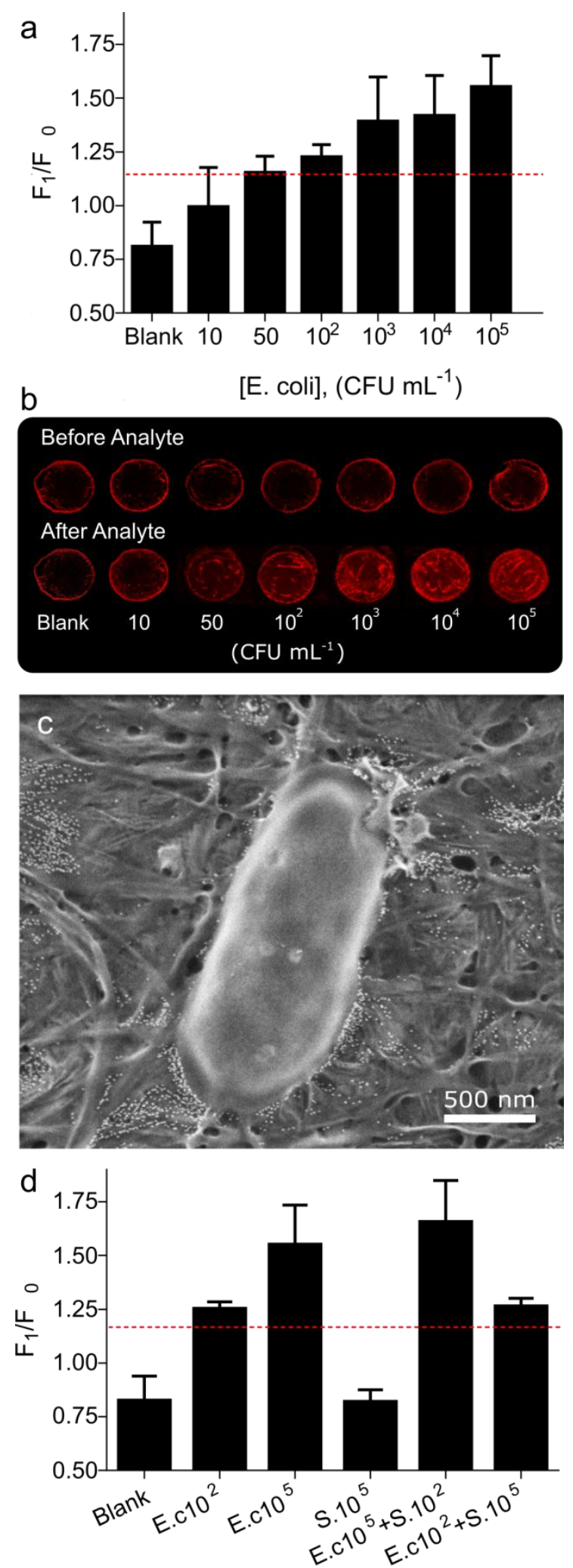

[Pathogen], (CFU mL ${ }^{-1}$ )

Figure 3. GONAP immunosensing platform for pathogen detection. a. Overall performance of $E$. coli detection in standard buffer. b. Photoluminescence images of GONAP immunosensing platform (before and after adding different concentrations of pathogen). $\mathbf{c}$. Scanning-electron micrographs of $E$. coli captured by GONAP immunosensing platform. $\mathbf{d}$. Study of the specificity of GONAP immunosensing platform targeting a model pathogen (E coli, E.c) in the presence of a non-target pathogen (S. typhimurium, $S$.). The threshold in red 


\section{WILEY-VCH}

(a, d) represents the limit of detection of the proposed device, which was estimated as the mean value of the blank samples plus three times their standard deviation. The error bars represent the standard deviation of at least three replicates.
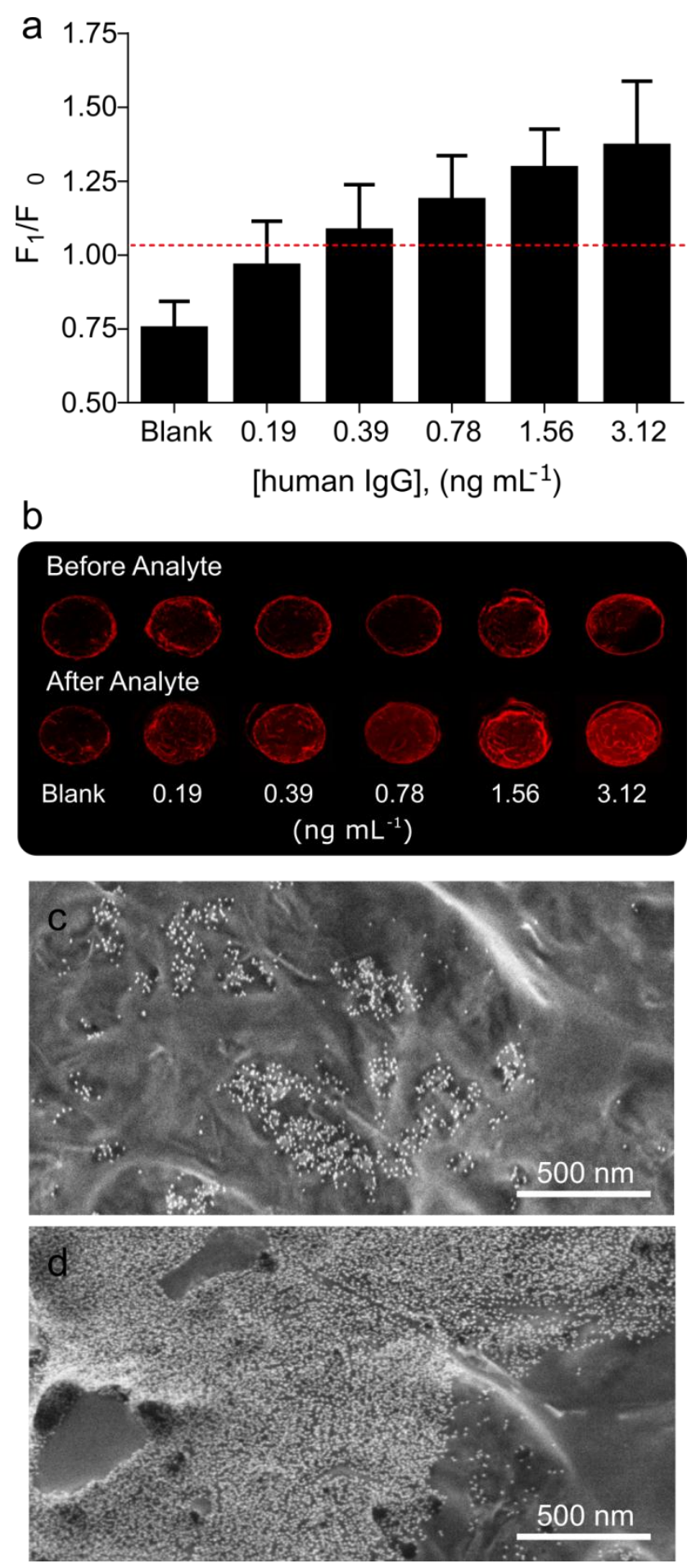

Figure 4. GONAP immunosensing platform for protein detection. a. Photoluminescent response for protein detection in standard buffer using monnoclonal anti-human IgG antibody $(\mathrm{mAb})$. b. Experimental evidence (scanned photo) of the photoluminescent intensity on GONAP before and after adding different concentrations of protein. c. Scanning-electron micrograph of human $\mathrm{IgG}$ at a concentration of $25 \mathrm{ng} \mathrm{mL}^{-1}$ in standard buffer. The target is 


\section{WILEY-VCH}

captured by the protein sensing platform using a polyclonal antibody. d. Scanning-electron micrographs of human IgG at a concentration of $3.12 \mathrm{ng} \mathrm{mL}^{-1}$ in standard buffer. The target is captured by the protein sensing platform using a monoclonal antibody.

Table 1. Spike and recovery assay results.

\begin{tabular}{ccccc}
\hline Real samples & $\begin{array}{c}\text { Spiked bacteria } \\
\text { [CFU } \mathrm{mL}^{-1} \\
\text { or } \mathrm{CFU}^{-1} \text { ] }\end{array}$ & $\begin{array}{c}\mathrm{F}_{1} / \mathrm{F}_{0} \text { a) } \\
\text { in standard buffer }\end{array}$ & $\begin{array}{c}\mathrm{F}_{1} / \mathrm{F}_{0} \text { b) } \\
\text { in real matrices }\end{array}$ & Recovery \% \\
\hline Poultry meat & $10^{2}$ & 1.145 & 1.118 & 97.60 \\
River water & $10^{3}$ & 1.205 & 1.184 & 98.30 \\
& $10^{4}$ & 1.396 & 1.305 & 93.47 \\
& $10^{2}$ & 1.101 & 1.061 & 96.35 \\
& $10^{3}$ & 1.231 & 1.201 & 97.60 \\
\hline $10^{4}$ & 1.359 & 1.323 & 97.30 \\
\hline
\end{tabular}

a) Performed in standard buffer; ${ }^{\text {b) }}$ performed in real matrices. The experiment was done by spiking $10^{2}, 10^{3}$ and $10^{4} \mathrm{CFU} \mathrm{mL} \mathrm{m}^{-1}$ of $E$. coli in standard buffer, poultry meat and river water $(\mathrm{n}=3$ for each sample), and the recovery percentages of bacteria from real samples were estimated by comparing with standard buffer.

Table 2. Spike and recovery assay results in human immunoglobulin (IgG/ $\operatorname{Ig} \mathrm{A} / \operatorname{IgM} / \operatorname{IgE})$ depleted serum

\begin{tabular}{cccc}
\hline $\begin{array}{c}\text { Spiked protein } \\
(\mathrm{ng} \mathrm{mL}-1)\end{array}$ & $\mathrm{F}_{1} / \mathrm{F}^{\mathrm{a})}$ & $\mathrm{F}_{1} / \mathrm{F}_{0} \mathrm{~b}^{\mathrm{b}}$ & Recovery \% \\
\hline $6.25(\mathrm{pAb})$ & 1.30 & 1.23 & 94.35 \\
$12.5(\mathrm{pAb})$ & 1.41 & 1.36 & 96.76 \\
$25(\mathrm{pAb})$ & 1.62 & 1.59 & 98.46 \\
$0.39(\mathrm{mAb})$ & 1.08 & 1.01 & 93.75 \\
$0.78(\mathrm{mAb})$ & 1.18 & 1.10 & 93.08 \\
$1.56(\mathrm{mAb})$ & 1.29 & 1.27 & 98.66 \\
\hline
\end{tabular}

a) Performed in standard buffer; ${ }^{\text {b) }}$ performed in human serum samples. The experiment was done by spiking $6.25,12.5$ and $25 \mathrm{ng} \mathrm{mL}-1$ of $\mathrm{HIgG}$ in standard buffer and human immunoglobulin $\operatorname{IgG} / \operatorname{Ig} \mathrm{A} / \operatorname{IgM} / \operatorname{IgE}$ depleted serum ( $\mathrm{n}=9$ for each sample), and the recovery percentages of protein from human serum depleted immunoglobulin samples were estimated by comparing with standard buffer. (pAb) Performed using a polyclonal antibody. (mAb) Performed using a monoclonal antibody. 


\section{WILEY-VCH}

Graphene oxide-coated nanopaper is introduced as an immunosensing platform, this virtually universal immunoassay approach avoids washing steps and facilitates rapid analysis without compromising its sensitivity.

\section{Biosensing}

N. Cheeveewattanagul, E. Morales-Narváezろ, A. H.A. Hassan, J. F. Bergua, W. Surareungchai, M. Somasundrum, A. Merkoçi*

Straightforward Immunosensing Platform based on Graphene Oxide-Decorated Nanopaper: A Highly Sensitive and Fast Biosensing Approach

ToC figure

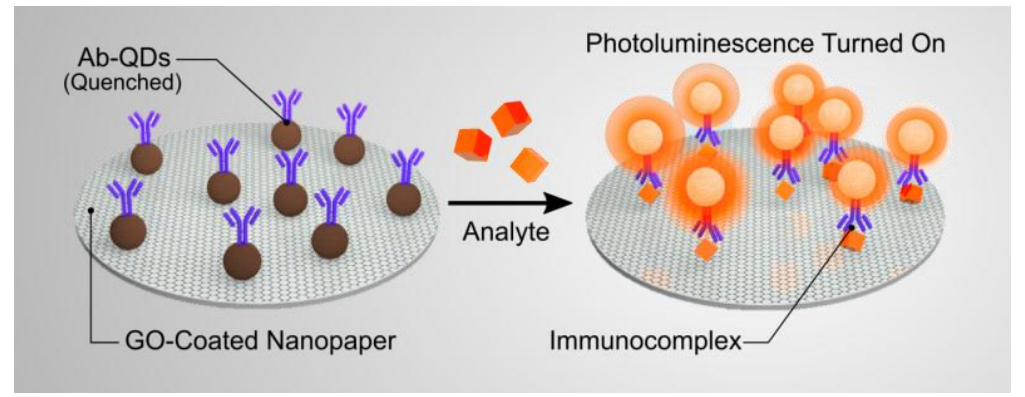

